\title{
AN OVERVIEW OF MICROCLIMATE TOOLS FOR PREDICTING THE THERMAL COMFORT, METEOROLOGICAL PARAMETERS AND DESIGN STRATEGIES IN OUTDOOR SPACES
}

\author{
${ }^{1}$ Mohammad S. ALBDOUR ${ }^{*}{ }^{2}$ Balint BARANYAI \\ ${ }^{1}$ Marcel Breuer Doctoral School, Faculty of Engineering and Information Technology \\ University of Pécs, Boszorkany u. 2, 7624 Pecs, Hungary, e-mail: albdour_m@yahoo.com \\ ${ }^{2}$ Department of Architectural Engineering, Faculty of Engineering and Information \\ Technology, Boszorkány u. 2 and János Szentágothai Research Center, Ifjúság u. 20 \\ University of Pécs, H-7624 Pécs, Hungary, e-mail: balint.baranyai@mik.pte.hu
}

Received 8 December 2018; accepted 21 March 2019

\begin{abstract}
There are several outdoor microclimatic simulation software tools in use. The current research aims to identify some of the most prominent computer-based tools based on their capacity of predicting a significant number of variables and compare them in order to establish their differences. This article provides an overview of the applications of computational fluid dynamics in outdoor performance simulation, focused on three topics: general criteria, specific outputs, strategies, and elements can be investigated by the tool. The results have shown that ENVI-met tool is capable of predicting and simulating the set microclimate variables.
\end{abstract}

Keywords: Predicting, Thermal comfort, Meteorological parameters, Design strategies, Outdoor spaces

\section{Introduction}

The energy demand of the built environment is almost $50 \%$ of the total energy demand of a national economy [1]. In the last decade, the scientific community has become interested in how urban design impacts outdoor thermal comfort. Enhancing the health and well-being of citizens, reducing heat and cold stress, and prolonging periods of comfort, are new focuses on design. For instance, it is today being investigated how the built environment alters local microclimates by influencing a series of thermodynamic phenomena. However, because of the dynamic nature of the urban environment, it is difficult to find a simulation tool that adequately models all of the

\footnotetext{
${ }^{*}$ Corresponding Author
} 
physical context types. Considering that in the last five years, researchers and designers have increasingly approached the modeling of microclimates, being aware of the modeling capabilities, and limitations of tools applicability has become critical [2].

Nowadays, designers need tools that answer to very specific questions even during the initial design phase [3]. Over the past 50 years, literally, tens of environmental programs have been developed, enhanced and are in use. The microclimate simulation programs are provided users with key microclimate performance indicators like air Temperature (Ta), Mean Radiant Temperature (MRT), Relative Humidity (RH), the Predicted Mean Vote (PMV), as well as wind speed. A number of comparative surveys of environmental programs have been published, ranging from comprehensive surveys of Computational Fluid Dynamics (CFD) simulation programs to reviews of single topics like radiation or relative humidity. Yet in the present study, it was found that no comprehensive comparative survey of tools had been conducted in the past five years [4]. This paper provides an in-depth study, which compares the features of eight primary microclimatic simulation software tools: Rayman, ENVI-met, ANSYS, Autodesk CFD, CitySim Pro, TAS, Meteodyn, Honeybee, and Ladybug. The developers of these tools provided initial detailed information and materials about their tools' capabilities and limitations.

\section{An overview of the eight programs}

\section{RayMan overview}

To assess the urban climate in a physiologically significant manner, it requires the use of methods of modern human-biometeorology, which deals with the effects of weather, climate and air quality on human organism. The tool (RayMan) estimates the radiation fluxes and the effects of clouds and solid obstacles on short wave radiation fluxes. The model, which takes complex structures into account, is suitable for utilization and planning purposes on the local and regional level. The final output of this model is the calculated mean radiant temperature, which is required in the energy balance model for humans. The final output of this model is the calculated mean radiant temperature, which is required in the energy balance model for humans. Consequently, it is also required for the assessment of urban bioclimate and thermal indices, like PMV, Physiologically Equivalent Temperature (PET), and Standard Effective Temperature (SET) [5].

\section{ENVI-met overview}

The importance of new green branches of science aiming to find solutions to environmental challenges has been internationally considered as undisputable [6]. The local microclimate is controlled by a multitude of different man-made and natural elements forming the urban landscape. They all have their individual character and constitute in their own way to the formation of wind flows, radiation patterns or air temperature. ENVI-met's team recognize as the outdoor thermal environment. ENVImet's can be used on urban microclimate and different fields like architecture, landscape architecture, urban planning, or human thermal comfort and health [7]. 
ENVI-met software was realized to be the most appropriate for the factors recognized compared to other tools for calculating outdoor variables. It is often updated free software developed for conducting outdoor studies, which concentrate on all the environmental dimensions as the soil, the atmosphere and all surfaces in the space. ENVI-met integrates all the essential factors available in the outdoor space, which provides reliable findings. ENVI-met is 3D software analyzing micro-scale thermal connections in urban environments. The model utilizes both the thermodynamic procedures happen at the ground surface, walls, roofs, and plants, in addition to the calculation of fluid dynamics features like turbulence and air flow. The software considers all kinds of solar radiation: direct, reflected and diffused. ENVI-met estimates the average radiant temperature. The calculation of radiation fluxes incorporates the plant shading, shielding, and absorption of radiation plus the re-radiation from other plant layers. It also has the benefit of integrating various types of vegetation estimating the plants' temperature, the vapor and heat exchange in the air canopy, which is an essential parameter for the current study. Additionally, the software is planned for micro-scale with a general time frame of 24 to 48 hours with a maximum time stop of $10 \mathrm{sec}$ and a 73 usual horizontal resolution from 0.5 to $10 \mathrm{~m}$. The resolution provides for calculating small scale relations among plants, buildings, and surfaces that are suitable for this study [8].

\section{Engineering simulation and 3D design software overview}

The designers can discover how engineering simulation is expanding across the entire product lifecycle, from digital exploration to digital prototyping to operations and maintenance using digital twins [9]. ANSYS is recognized as the world's leading fully integrated suite of computer-aided engineering tools. Solutions are broad and highly integrated, with advanced technology in all key areas including structural, CFD, thermal, dynamics, and meshing it enables organizations to predict with confidence that their products will thrive in the real world [10].

\section{Autodesk ${ }^{\circledR}$ CFD overview}

Computational fluid dynamics Autodesk ${ }^{\circledR}$ CFD software provides computational fluid dynamics and thermal simulation tools to help the designers to predict product performance, optimize designs, and validate product behavior before manufacturing [11]. Autodesk ${ }^{\circledR}$ CFD software provides flexible fluid flow and thermal simulation tools to help you make decisions earlier in the product development process. Easily explore and compare design alternatives and better understand the implications of design choices using an innovative design study environment and automation tools. Autodesk CFD software supports direct data exchange with most CAD software tools and Autodesk ${ }^{\circledR}$ Inventor ${ }^{\circledR}$ software, Autodesk ${ }^{\circledR}$ Revit ${ }^{\circledR}$ software, Creo ${ }^{\circledR}$, Pro/ENGINEER ${ }^{\circledR}$, and SolidWorks ${ }^{\circledR}[12]$.

\section{CitySim Pro overview}

The CitySim Pro tool is a free tool. However, import and export features need a login. Built on top of the CitySim solver, developed at the Solar Energy and Building Physics Laboratory of EPFL (École polytechnique fédérale de Lausanne), CitySim Pro is a 
graphical user interface aiming at the simulation and optimization of the sustainability of urban settlements. CitySim is fast (compared to other simulation engines), reliable (successfully tested against energy monitoring) and needs few input data (available at early design stages) [13].

Tas engineering overview

Tas is a suite of software products, which simulate the dynamic thermal performance of buildings and their systems. The main module is Tas building designer, which performs dynamic building simulation with integrated natural and forced airflow. It has a 3D graphics-based geometry input that includes a CAD link. Tas systems tool is a Heating, Ventilation, and Air Conditioning (HVAC) systems/controls simulator, which may be directly coupled with the building simulator. It performs automatic airflow and plant sizing and total energy demand. The third module, Tas Ambiens, is a robust and simple to use 2D CFD package, which produces a cross section of microclimate variation in a space. Tas combines dynamic thermal simulation of the building structure with natural ventilation calculations, which include advanced control functions on aperture opening and the ability to simulate complex mixed mode systems. The software has heating and cooling plant sizing procedures, which include optimum start. Tas has 20 years of commercial use around the world [5], [14].

\section{Meteodyn overview}

Since 2003, Meteodyn's team have studied micro-meteorology at a local scale (wind, solar radiation and precipitation) in order to optimize microclimate projects. Also, they develop applied meteorology software (wind and solar resource assessment, natural ventilation, outdoor climatic comfort, etc.). Meteodyn's expertise is acknowledged in more than 40 countries around the world [15].

\section{Ladybug \& Honeybee tools overview}

Ladybug \& Honeybee tools are a collection of free computer applications that support environmental design and education of all the available environmental design software packages, Ladybug tool is among the most comprehensive, connecting 3D Computer-Aided Design (CAD) interfaces to a host of validated simulation engine. Honeybee connects Grasshopper 3D to validated simulation engines like EnergyPlus, Radiance, Daysim and Open Studio for building energy, comfort, day-lighting and lighting simulation [16].

\section{Objective}

1. An overview of the computational fluid dynamics tools applications in microclimate simulation;

2. Choosing the most suitable computer-aided tool for predicting the outdoor thermal comfort, meteorological parameters as well as outdoor design strategies. 


\section{Methodology}

The research briefly described here contains detailed tables comparing the features and capabilities of the programs in the following categories:

1. General criteria (User interface, reliability and accuracy, cost, operating system, compatibility, visualization and graphics, comfort prediction index);

2. Specific outputs (PMV, PET, Predicted Percentage of Dissatisfied (PDD), mean radiant temperature, relative humidity, air temperature, wind speed, wind direction, solar radiation, sky-view factor, Carbon dioxide $\left(\mathrm{CO}_{2}\right)($;

3. Strategies and elements can be investigated by the tool in outdoor spaces (plantation, materials and Albedo, waterbody, green roofs, green walls, shading, streets canyon geometry, streets wind orientation, building form and shape, buildings height, site landform, heat sinks, urban form, building adjacency, buildings arrangement, building envelope, building roof shape, natural ventilation: inducers, shafts, projections, double skin façade).

All information and data in this research are provided by program developers on their websites, tutorials, and help/support forums as well as published papers. The eight selected programs are RayMan, ENVI-met, ANSYS package, Autodesk CFD, CitySim Pro, TAS, Meteodyn, Ladybug, and Honeybee. Although other computer programs are capable of predicting the outdoor thermal comfort, meteorological parameters and design strategies in outdoor spaces, they will not be discussed here due to publication limitations. It is known that the simulation research methods can be effectively used where the experimental work in the real world cannot be performed due to unacceptable ethical, economic or dangerous restrictions [17]. In simple terms, outdoor thermal comfort software technique uses a complex mathematical model that is represented and solved by a computer program. The results are graphically presented, usually on a 2D or and 3D. There is an increasing range of outdoor thermal simulation software tools available, with the ability to calculate increasingly complex environmental and energy requirements, with more variables and a more rigorous approach. Several computeraided tools can predict the following microclimate variables:

- External air movement patterns and airspeed;

- Wind direction;

- Air temperature;

- Relative humidity;

- Global solar radiation;

- Sky-factor;

- Predicted mean vote value;

- Mean radiant temperature;

- $\mathrm{CO}_{2}$ level.

Several decision-making tools were considered; Rayman, ENVI-met, ANSYS package, Autodesk package, CitySim Pro, TAS, Meteodyn, Honeybee as well as Ladybug. 


\section{Results and discussion}

Each software tool of the mentioned microclimate simulation tools has certain characteristics and specific outputs and use in outdoor simulation. In order to better understand the specific features of each one, (Table I), (Table II), (Table III) and (Table $I V)$ present a detailed table of the features of each of the software tools stated above.

- ANSYS has very high compatibility with the friendly user interface and high precision (Table I). However, the cost is also high, for this reason. The computer-aided tool ANSYS was excluded due to its high price and its complexity. Furthermore, the software is not capable of predicting thermal indices in outdoor spaces (Table I).

Table I

Detailed comparison of CFD software serving the scope of the research (General criteria and Specific outputs)

\begin{tabular}{|c|c|c|c|c|}
\hline Choosing Criteria & RayMan & Envi-met & ANSYS & $\begin{array}{c}\text { Autodesk } \mathbb{R} \\
\text { CFD }\end{array}$ \\
\hline \multicolumn{5}{|c|}{ General criteria } \\
\hline User Interface & Friendly & Friendly & $\begin{array}{l}\text { Extremely } \\
\text { Complex }\end{array}$ & Friendly \\
\hline Reliability \& Accuracy & High & High & Very High & High \\
\hline Cost & Free & Low & Very High & Free \\
\hline Operating System & Windows & Windows & $\begin{array}{c}\text { Windows and } \\
\text { MAC }\end{array}$ & Windows \\
\hline Compatibility & Low & Moderate & High & Very High \\
\hline $\begin{array}{c}\text { Visualization and } \\
\text { Graphics }\end{array}$ & Moderate & High & High & High \\
\hline Comfort Prediction Index & PET & PMV & - & - \\
\hline \multicolumn{5}{|c|}{ Specific Outputs } \\
\hline PMV & Yes & Yes & No & No \\
\hline PET & Yes & Yes & No & No \\
\hline PDD & Yes & Yes & No & No \\
\hline MRT & Yes & Yes & Yes & Yes \\
\hline Relative Humidity & Yes & Yes & Yes & No \\
\hline Air Temperature & Yes & Yes & Yes & Yes \\
\hline Wind Speed & No & Yes & Yes & Yes \\
\hline Wind Direction & No & Yes & Yes & Yes \\
\hline Solar Radiation & Yes & Yes & Yes & Yes \\
\hline Sky-view Factor & Yes & Yes & Yes & Yes \\
\hline $\mathrm{CO}_{2}$ & No & Yes & Yes & Yes \\
\hline
\end{tabular}


- Envi-met is capable of predicting and simulating the thermal comfort indices (PMV, PET, MRT and PDD), meteorological parameters (airspeed, wind direction, air temperature, relative humidity, global solar radiation) as well as most of the design strategies in outdoor spaces. Therefor ENVI-met has been chosen as the most suitable tool among the eight tools.

\section{Table II}

Detailed comparison of CFD software serving the scope of the research (Strategies and elements can be investigated by the tool in outdoor environment)

\begin{tabular}{|c|c|c|c|c|}
\hline \multicolumn{5}{|c|}{ Strategies and elements can be investigated by the tool in outdoor environment } \\
\hline Plantation & Yes & Yes & No & No \\
Materials and Albedo & Yes & Yes & Yes & No \\
Waterbody & No & Yes & Yes & Limited \\
Green Roofs & No & Limited & Limited & Limited \\
Green Walls & No & Limited & Limited & Limited \\
Shading & Yes & Yes & Yes & Yes \\
Streets Canyon Geometry & No & Yes & Yes & Yes \\
Streets Wind Orientation & No & Yes & Yes & Yes \\
Building Form and Shape & No & Limited & Yes & Yes \\
Buildings Height & Limited & Yes & Yes & Yes \\
Site Landform & No & No & Yes & Yes \\
Heat Sinks & No & yes & Yes & Yes \\
Urban Form & Limited & Yes & Yes & Yes \\
Building Adjacency & Limited & Limited & Yes & Yes \\
Buildings Arrangement & Limited & Yes & Yes & Yes \\
Building Envelope & No & No & Yes & Yes \\
Building Roof Shape & No & No & Yes & Yes \\
Natural Ventilation & No & Limited & Yes & Yes \\
Inducers, Shafts, & & & & \\
Projections, Double Skin & & & & \\
Façade & & & & \\
Final Results & Excluded & Chosen & Excluded & Excluded \\
\hline
\end{tabular}

- RayMan is a free tool with high accuracy (Table I), however. The tool is not capable of investigating primary design strategies like waterbody, green roofs and green walls (Table II). Furthermore. The computer-aided software is not capable of predicting wind speed with low Compatibility (Table I), so the tool was excluded.

- Autodesk ${ }^{\circledR}$ CFD is a free tool with high precision and friendly user interface (Table I), however. The software is not capable of predicting thermal indices in outdoor spaces (Table II). As a result, the tool has been excluded. 
- Tas and Meteodyn have a relatively low price with friendly User Interface as well as high and moderate Compatibility (Table III), however. Both tools are not capable of predicting thermal indices in outdoor spaces (Table IV), so were excluded.

- CitySim Pro is a free computer-aided software with friendly User Interface and online operating system. However, its Compatibility with other computer-aided tools is low (Table IV), therefore, the tool has been excluded.

- Ladybug and Honeybee are free decision-making tools with friendly user interface and high compatibility (Table III). However, the tools are not capable of simulating main thermal indices like the PMV and PET in outdoor spaces neither capable of predicting the relative humidity (Table IV), for this reason, the tool has been excluded.

Table III

Detailed comparison of CFD software serving the scope of the research (General criteria and Specific outputs)

\begin{tabular}{|c|c|c|c|c|}
\hline Choosing Criteria & $\begin{array}{l}\text { CitySim } \\
\text { Pro } \\
\end{array}$ & TAS & Meteodyn & $\begin{array}{c}\text { Ladybug and } \\
\text { Honeybee }\end{array}$ \\
\hline \multicolumn{5}{|c|}{ General Criteria } \\
\hline User Interface & Friendly & Friendly & Friendly & Friendly \\
\hline Accuracy & moderate & High & Moderate & Very High \\
\hline Cost & Free & Low & Low & Free \\
\hline Operating System & Online & Windows & Windows & $\begin{array}{l}\text { Windows and mac } \\
\text { and Linux }\end{array}$ \\
\hline Compatibility & Low & High & Moderate & Very High \\
\hline $\begin{array}{c}\text { Visualization and } \\
\text { Graphics }\end{array}$ & Moderate & High & High & High \\
\hline $\begin{array}{l}\text { Comfort Prediction } \\
\text { Index }\end{array}$ & PET & PDD & No & SET \\
\hline \multicolumn{5}{|c|}{ Specific Outputs } \\
\hline PMV & No & No & No & No \\
\hline PDD & No & Yes & No & No \\
\hline PET & Yes & No & No & No \\
\hline MRT & Yes & Yes & No & Yes \\
\hline Relative Humidity & No & Yes & No & No \\
\hline Air Temperature & Yes & Yes & Yes & Yes \\
\hline Wind Speed & Yes & Yes & Yes & Yes \\
\hline Wind Direction & Yes & Yes & Yes & Yes \\
\hline Solar Radiation & Yes & Yes & No & Yes \\
\hline Sky-Wiew Factor & Yes & Yes & No & Yes \\
\hline $\mathrm{CO}_{2}$ & No & Yes & No & No \\
\hline
\end{tabular}




\section{Table IV}

Detailed comparison of CFD software serving the scope of the research (Strategies and elements can be investigated by the tool in outdoor environment)

\begin{tabular}{|c|c|c|c|c|}
\hline \multicolumn{5}{|c|}{ Strategies and elements can be investigated by the tool in outdoor environment } \\
\hline Plantation & No & No & No & Yes \\
\hline Materials and Albedo & No & Yes & No & Yes \\
\hline Waterbody & No & No & Yes & No \\
\hline Green Roof & No & No & No & Yes \\
\hline Green Wall & No & No & No & Yes \\
\hline Shading & Yes & Yes & Yes & Yes \\
\hline $\begin{array}{l}\text { Streets Canyon } \\
\text { Geometry }\end{array}$ & Yes & Yes & Yes & Yes \\
\hline $\begin{array}{l}\text { Streets Wind } \\
\text { Orientation }\end{array}$ & Yes & Yes & Yes & Yes \\
\hline $\begin{array}{c}\text { Building Form and } \\
\text { Shape }\end{array}$ & Limited & Yes & Yes & Yes \\
\hline Buildings Height & Yes & Yes & Yes & Yes \\
\hline Site Landform & No & Yes & Yes & Yes \\
\hline Heat Sinks & Yes & Yes & Yes & No \\
\hline Urban Form & Yes & Yes & Yes & Yes \\
\hline Building Adjacency & Yes & Yes & Yes & Yes \\
\hline Buildings Arrangement & Yes & Yes & Yes & Yes \\
\hline Building Envelope & Limited & Yes & No & Limited \\
\hline Building Roof Shape & Yes & Yes & No & Yes \\
\hline $\begin{array}{l}\text { Natural Ventilation } \\
\text { Inducers, Shafts, } \\
\text { Projections, Double } \\
\text { Skin Façade }\end{array}$ & Limited & Yes & Limited & Limited \\
\hline Final Results & Excluded & Excluded & Excluded & Excluded \\
\hline
\end{tabular}

\section{Conclusion}

Currently, there are several microclimate simulation software tools with different levels of complexity and response to different variables. Among the complete simulation tools are Rayman, ENVI-met, ANSYS package, Autodesk package, CitySim Pro, TAS, Meteodyn, Honeybee, and Ladybug. The author found that among several microclimate simulation tools ENVI-met is capable of predicting and simulating the thermal comfort indices (PMV, PET, MRT and PDD), meteorological parameters (airspeed, wind direction, air temperature, relative humidity, global solar radiation) as well as most of the design strategies in outdoor spaces. Therefor ENVI-met has been chosen as the most suitable tool among the eight tools. 


\section{Open Access statement}

This is an open-access article distributed under the terms of the Creative Commons Attribution 4.0 International License (https://creativecommons.org/licenses/by/4.0/), which permits unrestricted use, distribution, and reproduction in any medium, provided the original author and source are credited, a link to the CC License is provided, and changes - if any - are indicated. (SID_1)

\section{References}

[1] Baranyai B., Kistelegdi I. Energy management monitoring and control of public buildings, Pollack Periodica, Vol. 9, No. 2, 2014, pp. 77-79.

[2] Naboni E., Meloni M., Coccolo S., Kaempf J., Scartezzini J. L. An overview of simulation tools for predicting the mean radiant temperature in an outdoor space, Energy Procedia, Vol. 122, 2017, pp. 1111-1116.

[3] Sousa J. Energy simulation software for buildings: Review and comparison, http://ceurws.org/Vol-923/paper08.pdf, (last visited 25 November, 2018).

[4] Crawley D. B., Hand J. W., Kummert M., Griffith B. T. (2008). Contrasting the capabilities of building energy performance simulation programs, Building and Environment, Vol. 43, No. 4, 2008, pp. 661-673.

[5] Matzarakis A., Rutz F. Application of the Rayman model in urban environments, https://ams.confex.com/ams/pdfpapers/169963.pdf, (last visited 27 November 2018).

[6] Póth B., Kistelegdi I. The history of the energy and climate concept of the szentágothai research center, Pollack Periodica, Vol. 8, No. 3, 2013, pp. 3-14.

[7] ENVI-met Overview, https://www.envi-met.com/overview/, (last visited 27 November 2018).

[8] Taheri F. Impact of modified urban surfaces on enhancing the microclimate of residential landscape areas in hot arid environments - Case study of Jumeirah Village Circle Community, Dubai, MSc Thesis, The British University in Dubai, 2015.

[9] ANSYS, Simulation Capabilities, ANSYS Icepak, ANSYS Inc, www.ansys.com/, (last visited 22 November 2018).

[10] ANSYS, Overview, https://caeai.com/ansys-software-support/ansys-overview, (last visited 22 November 2018).

[11] Computational fluid dynamics software, CAD Software, 2D and 3D computer-aided design, Autodesk, Redshift EN, www.autodesk.com/products/cfd/overview, (last visited 24 November 2018).

[12] Predict product performance with simulation, www.synergis.com/wpcontent/uploads/2015/09/Simulation-Portfolio-2016-Overview-Brochure.pdf, (last visited 27 November 2018).

[13] Kämpf, Jérôme, Download, Kaemco, Download, kaemco.ch/download.php. (last visited 26 November 2018).

[14] Tas Engineering - EDSL, https://www.edsl.net/tas-engineering/, (last visited 25 November 2018).

[15] Wind engineering and climatology, https://meteodyn.com/en/, (last visited 26 November 2018).

[16] Ladybug Tools, Epwmap, www.ladybug.tools/, (last visited 28 November 2018).

[17] Groat L. N., Wang D. Architectural research methods, 2nd Edition, 2013. 